\section{Technical Analysis and the Profitability of U.S. Foreign Exchange Intervention}

\author{
Christopher J. Neely
}

\section{D)}

ecent research has discovered two seemingly contradictory facts about U.S. intervention in foreign exchange markets. On the one hand, extrapolative technical trading rules trade against U.S. foreign exchange intervention and produce excess returns- returns in excess of nominal interest rates-during these periods, and U.S. intervention itself, is profitable over long periods. LeBaron (1996) and Szakmary and Mathur (1997) have shown that excess returns to technical trading rules are high during periods of central bank intervention and that the technical rules trade contrary to the direction of official intervention. Along the same lines, Neely and Weller (1997) have shown that trading rules constructed by genetic programs can use information on the direction of U.S. intervention to increase their excess returns in some exchange rates: When the Federal Reserve is buying dollars, traders following technical rules are usually selling dollars and profiting handsomely. Some-Dooley and Shafer (1983), Corrado and Taylor (1986), Sweeney (1986), Friedman (1988), and Kritzman (1989) - have interpreted these results to confirm long-held conjectures that U.S. authorities' intervention creates excess returns for speculators and that public resources are being lost to speculators.
These results certainly suggest that investors should trade contrary to U.S. intervention. In contrast, Leahy (1995) has found that U.S. foreign exchange intervention has been profitable for U.S. authorities, so perhaps investors would be wise to trade with them.

The relationship between trading-rule returns and central bank intervention is important because it might shed light on the source of technical trading-rule profits that seem to contradict the efficientmarkets hypothesis. The profitability of U.S. intervention operations has been studied primarily because of Friedman's (1953) argument that there is a connection between the profitability of intervention and the ability of intervention to stabilize the market. ${ }^{1}$ This link is tenuous, however. Salant (1974), Mayer and Taguchi (1983), and De Long, Shleifer, Summers, and Waldmann (1989) provide counterexamples.

How can technical traders make excess returns when they take positions contrary to U.S. intervention while U.S. intervention itself is profitable? On whom is the smart money to bet? This article first extends recent research linking U.S. intervention and trading-rule returns. It then confirms that U.S. intervention has been profitable over long periods. Finally, the article presents some explanations, consistent with the data, that may reconcile this apparent contradiction.

\section{CENTRAL BANK INTERVENTION}

Central bank intervention is the practice of monetary authorities buying and selling currency in the foreign exchange market to influence exchange rates. In the United States, for example, the Federal Reserve and the U.S. Treasury generally collaborate on foreign exchange intervention decisions, and the Federal Reserve Bank of New York conducts operations on behalf of both. ${ }^{2}$

\footnotetext{
${ }^{1}$ Friedman (1953) was referring more generally to speculation in foreign exchange and discussed government speculation (intervention) as a special case. Sweeney (1997) reviews research on the profitability of central bank intervention.

2 Humpage (1994) outlines the institutional aspects of U.S. intervention while Edison (1993) reviews the extensive literature on central bank intervention.
} 
When a central bank buys (sells) its own currency in exchange for a foreign currency, it decreases (increases) the amount of its currency in circulation, lowering (raising) its domestic money supply. By itself, this transaction would influence exchange rates in the same way as ordinary domestic open market operations; however, most central banks routinely "sterilize" their foreign exchange operations; that is, they buy and sell domestic bonds to reverse the effect of the foreign exchange operation on the domestic money supply (Edison, 1993). For example, if the Federal Reserve Bank of N ew York bought $\$ 100$ million worth of deutschemarks (DM) in a foreign exchange intervention, the U.S. monetary base would increase by $\$ 100$ million in the absence of sterilization. Other things equal, interest rates and prices would also change. To prevent changes to domestic interest rates and prices, the Federal Reserve Bank of $\mathrm{New}$ York would sterilize the intervention-sell $\$ 100$ million worth of government securities- and absorb the liquidity. Complete sterilization would also require that the foreign central bank - the Bundesbank in the case of the DM - automatically reverse the effect of the intervention on the foreign money market by increasing the supply of foreign currency through open market operations. The net effect would be to increase the relative supply of U.S. government securities versus foreign securities on the market but to leave the domestic and foreign money supplies unchanged.

Because fully sterilized intervention does not affect either prices or interest rates, it does not influence the exchange rate directly, as does ordinary monetary policy. There are two channels through which official intervention might affect the foreign exchange market indirectly - the portfolio balance channel and the signaling channel. Sterilized intervention leaves the money supply unchanged but changes the relative supplies of bonds denominated in different currencies. The portfolio balance channel theory holds that if these bonds are imperfect substitutes, investors must be compensated to hold the relatively more numerous bonds with a higher expected return. This higher expected return must result from a change in either the price of the bonds or the exchange rate. The signaling channel, on the other hand, suggests that official intervention communicates or signals to the market information about future monetary policy or the long-run equilibrium value of the exchange rate. Both the portfolio balance and signaling channels provide a theoretical transmission mechanism from sterilized intervention to exchange rate changes. There is little empirical evidence to support the contention that there is a strong influence from either channel; the general consensus has been that any influence intervention has on the exchange rate is relatively weak and temporary. ${ }^{3}$

The Foreign Currency Directive of the Federal Reserve System directs intervention to "counter disorderly market conditions," in cooperation with foreign central banks, consistent with the International M onetary Fund Article IV, Section 1, that forbids attempts to remedy balanceof-payments problems by manipulating exchange rates. 4 "Disorderly market conditions" are not precisely defined, so the concept is open to interpretation. Reasons for intervention might include reducing volatility in the market or preventing abrupt changes in exchange rates. Alternatively, a central bank might intervene to correct "misalignments," that is, over- or undervaluations of the exchange rate. Such intervention might work by communicating information to market participants about the long-run value of the exchange rate.

U.S. intervention often is conducted against a prevailing trend in the market ("leaning against the wind"). In other words, U.S. authorities tend to buy dollars when the foreign exchange price of dollars is declining. Whether the intervention occurs during periods of high volatility or changes the volatility of exchange rates is not clear.

Table 1 shows some summary statistics on daily U.S. intervention data, in millions of U.S. dollars, over the period from March 1, 1973, to December 31, 1996. ${ }^{5}$ Positive 
numbers indicate purchases of dollars; negative numbers indicate sal es of dollars. The intervention data in the table are described in two ways: (1) as the sum of in-market and with-customer intervention and (2) as solely in-market intervention. In-market interventions are designed to influence the exchange rate directly, while with-customer interventions are transactions with other government entities that also change the relative supplies of domestic and foreign bonds. Adams and Henderson (1983) cite the example of a central bank that is supplying foreign exchange out of its reserves for its government to repay obligations denominated in a foreign currency. The in-market definition and the sum of in-market and with-customer intervention definitions produce much the same summary statistics. In-market intervention occurred on about 16 percent of business days in the DM and 4 percent of days in the yen (JY). Because intervention was relatively evenhanded, with almost as many dollars bought as sold during the period, the mean level of intervention was small. When intervention did occur, it was small-in absolute valuerelative to the size of the foreign exchange market. The mean absolute level of inmarket intervention was about $\$ 80$ million for the DM and $\$ 130$ million for the yen. In contrast, the daily volume of transactions in all foreign exchange markets over a typical business day was $\$ 1.2$ trillion in April 1995, with the dollar involved in 83 percent of those transactions (Bank for International Settlements, 1996). 6

The last two rows show that interventions tend to be clustered together in time. The probability of non-zero in-market intervention in the DM is only 7 percent if there has been no intervention on the prior day, but 44 percent if intervention has occurred on that day.

\section{TECHNICAL TRADING RULES AND U.S. INTERVENTION}

A strong and consistent result in international finance is the evidence that technical trading rules- rules that use

\section{Table 1}

Summary Statistics on U.S. Intervention, March 1, 1973, to December 31, 1996

\begin{tabular}{|c|c|c|c|c|}
\hline & \multicolumn{2}{|c|}{ In-Market+w ith Customer } & \multicolumn{2}{|c|}{ In-market } \\
\hline & $\mathrm{DM} / \$$ & $\mathrm{JY} / \$$ & $\mathrm{DM} / \$$ & $\mathrm{~J} / \$$ \\
\hline Number of Interventions & 1198 & 287 & 971 & 243 \\
\hline Mean ||$I \neq 0$ & 5.61 & 2.74 & 11.19 & 4.91 \\
\hline Mean $|I||| \neq 0$ & 68.32 & 112.55 & 79.65 & 131.23 \\
\hline Minimum I & -797 & -555 & -797 & -555 \\
\hline Maximum I & 950 & 800 & 950 & 800 \\
\hline$P(I(t) \neq 0 \mid I(t-1)=0)$ & 0.08 & 0.02 & 0.07 & 0.02 \\
\hline$P(I(t) \neq 0 \mid I(t-1) \neq 0)$ & 0.50 & 0.43 & 0.44 & 0.42 \\
\hline
\end{tabular}

NOTES: The first two columns refer to the sum of daily in-market and with-customer interventions, while columns three and four refer solely to in-market interventions. Positive numbers indicate purchases of dollars; negative numbers indicate sales of dollars. The second and third rows are the mean and the mean absolute level of (non-zero) intervention. The sixth and seventh rows are the probabilities of (non-zero) intervention, given that the previous day's, intervention levels were zero and non-zero respectively.

information on past prices to determine trading decisions- can generate persistent profits in dollar exchange rate markets. ${ }^{7}$ This success is puzzling because it seems to contradict the efficient-markets hypothesis that holds that no trading strategy should be able to generate unusual profits on publicly available information-like past prices- except by bearing unusual risk. In other words, expected risk-adjusted excess returns should be zero. Efforts to explain the profitability of trading rules as the compensation for holding risky assets have been largely unconvincing. Because risk is difficult to model and measure, however, it remains unclear to what degree the positive excess returns can be explained by risk, transactions costs, market inefficiencies, or other factors.

All technical trading rules attempt to filter the data to discover trends in exchange rates. So-called double moving-average rules (MA rules) are among the most successful and often-studied type of mechanical trading rule. A double movingaverage rule prescribes buying an assete.g., a foreign currency-denominated bank deposit- if a moving average of past exchange rates over a short time window is greater than a moving average of past exchange rates over a longer time window.

\footnotetext{
${ }^{6}$ In the foreign exchange market, one trade may generate many others as traders seek to "square" their positions before the end of business. Therefore, the level of intervention may look deceptively small compared to the enormous foreign exchange market volume.

${ }^{7}$ Neely (1997) discusses the use and testing of technical trading rules.
} 
${ }^{8}$ The signals generated by the moving-average rule could depend on whether the exchange rate is defined as dollars per unit of foreign currency or units of foreign currency per dollar. In practice, however, the correlation in the signals generated by the two methods exceeds 99 percent, and the returns are nearly identical.

${ }^{9}$ In this and all other exercises in this article, transactions costs are ignored. Past research on technical trading rules has shown the results to be relatively insensitive to the inclusion or exclusion of reasonable transactions costs. Research on the size of transactions costs in the foreign exchange market indicates that, for large transactions, buying or selling $\$ 1$ will cost the trader $\$ 0.00025$.

${ }^{10}$ The form of Equation 3 is due to the fact that the short trader receives twice the U.S. rate of return - from the margin account and from the converted DM - while losing the return to the DM. This sum is then divided by the gross domestic interest rate to obtain Equation 3.

${ }^{11}$ This definition of $r_{t}$ introduces a very small approximation error in the case of a short position.
Conversely, if the short moving average is less than the long moving average, the rule instructs that the trader should sell the asset. The length of the moving averages is determined by trial and error by traders. In this article, we will follow LeBaron's (1996) lead and choose 1 as the length of the short moving average and 150 as the length of the long moving average. This MA $(1,150)$ rule can be written as follows:

$$
\begin{aligned}
& \text { Buy if } S_{t} \geq \frac{1}{150} \sum_{i=0}^{149} S_{t-i}, \text { and } \\
& \text { sell if } S_{t}<\frac{1}{150} \sum_{i=0}^{149} S_{t-i},
\end{aligned}
$$

where $S_{t}$ is the spot dollar price of foreign exchange at time ${ }^{8}{ }^{8}$

To determine whether the rule is profitable, we assume that a trader holds an amount of money - say $\$ 1,000$ - in a margin account that collects the U.S. interest rate. If the moving-average rule directs the trader to buy DM, the trader borrows $\$ 1,000$, using the margin as collateral, and converts the borrowed money to a DM investment at the spot exchange rate. The dollar rate of return on the DM investment is the product of the overnight German interest rate and the rate of appreciation of the DM against the dollar. The investor must also pay interest on the dollars that were borrowed. The gross excess return to this strategy over simply holding the margin account is ${ }^{9}$

$$
R_{t}=\frac{\frac{S_{t+1}}{S_{t}}\left(1+i_{t}^{D M}\right)}{\left(1+i_{t}^{\$}\right)},
$$

where $i_{t}^{D M}$ is the German overnight interest rate, $S_{t+1} / S_{t}$ is the appreciation of the DM against the dollar overnight, and $i_{t^{5}}$ is the U.S. overnight interest rate. If the trader receives a signal to sell the $D M$, he borrows $\$ 1,000$ worth of DM - using the $\$ 1,000$ in his margin account as securityconverts those DM to a dollar-denominated bank account and obtains the following gross excess return-over holding a margin account-on the short DM position: ${ }^{10}$
(3)

$$
R_{t}=2-\frac{\frac{S_{t+1}}{S_{t}}\left(1+i_{t}^{D M}\right)}{\left(1+i_{t}^{\$}\right)} .
$$

The continuously compounded (log) excess returns are denoted by $z_{t} r_{t}$, where $z_{t}$ is an indicator variable taking the values of +1 for a long position and -1 for a short position, and $r_{t}$ is defined as ${ }^{11}$

$$
\begin{aligned}
r_{t} & =\ln S_{t+1}-\ln S_{t}+\ln \left(1+i_{t}^{*}\right) \\
& -\ln \left(1+i_{t}\right) .
\end{aligned}
$$

The total excess return, $r$, for a trading rule over the period from time zero to time $\mathrm{T}$ is given by:

$$
r=\sum_{t=0}^{T-1} z_{t} r_{t} .
$$

To test the profitability of the MA $(1,150)$ rule, we obtained daily noon (Eastern time) buying rates in N ew York City for the $\$ / D M$ and $\$ / J Y$ exchange rates. These data are available in the $\mathrm{H} .10$ Federal Reserve statistical release. The Bank for International Settlements (BIS) provided the daily overnight interest rates, collected at 9:00 a.m. London time. The exchange rate data and interest rate data run from March 1, 1973, through January 2, 1997, the first business day of 1997.

Panel A of Table 2 shows the results of testing the MA $(1,150)$ rule on the \$/DM and $\$ / / Y$ exchange rate over the sample period. The rule was very profitable, producing a 5.6 percent annual return for the \$/DM and an 8.4 percent annual return for the $\$ / / Y$. The returns are highly significant statistically, whether we use conventional asymptotic significance levels or bootstrap the returns to obtain smallsample critical values. The rules trade four to seven times a year and produce very high returns relative to volatility with Sharpe ratios of 0.53 and 0.86 , respectively. In comparison, the Sharpe ratio to a buy-and-hold strategy for the S\& $P 500$ over a similar period is 0.3 . These results are consistent with past results in the technical trading rule literature, which suggests that following 
moving-average trading rules can generate excess returns that are difficult to explain in terms of standard risk measures. ${ }^{12}$

$M$ any authors-Dooley and Shafer (1983), Corrado and Taylor (1986), Sweeney (1986), Friedman (1988), and Kritzman (1989) - have cited the existence of central bank intervention in foreign exchange markets as a potential explanation for the profitability of technical trading rules. The rationale for that theory is as follows: Because intervention is conducted to maintain orderly market conditions or perhaps to achieve macroeconomic goals such as price stability or full employment, rather than to make money, central banks may be willing to take a loss on their trading. LeBaron (1996) found that most trading-rule profits were generated on the day before in-market U.S. intervention. Szakmary and Mathur (1997) examine the link between trading-rule returns and proxies for central bank intervention in the form of monthly foreign exchange reserves. They find that for three of five exchange rates, including the \$/DM and $\$ / J Y$, "trading-rule profits different than zero can be fully explained by "leaning against the wind intervention' by central banks" (Szakmary and Mathur (1997), p. 531). They speculate that trading-rule profits may represent a transfer from central banks to technical traders. The monthly frequency of the data used by Szakmary and Mathur (1997), however, limits the information one can gather from their exercise.

To investigate this claim, we will follow LeBaron's procedure and selectively examine the trading rule results after removing those returns from day $t$ to $t+1$ for which intervention was non-zero on $t+1$. We will also examine results after removing returns from day $t$ to $t+1$ for which intervention was non-zero on day $t$. According to Goodhart and Hesse (1993) and Humpage (1998), most intervention is conducted before noon in New York, before the close of the European markets. Because the exchange rate data were collected at noon, intervention on day $t$ should have its greatest effect on returns from $t-1$ to $t$ or from $t$ to $t+1 .{ }^{13}$

\begin{tabular}{|c|c|c|c|}
\hline \multicolumn{4}{|c|}{$\begin{array}{l}\text { MA }(1,150) \text { Trading Rule } \\
\text { Results, March } 1,1973 \text { to } \\
\text { December } 31,1996 .\end{array}$} \\
\hline & & \$ DM & $\$ / J Y$ \\
\hline \multirow{7}{*}{$\begin{array}{l}\text { Panel A: } \\
\text { All observations }\end{array}$} & $\mathrm{N}$ & 5982 & 5982 \\
\hline & $100 * A R$ & 5.64 & 8.41 \\
\hline & $100 *$ std. & 0.67 & 0.62 \\
\hline & tstatistic & 2.60 & 4.20 \\
\hline & Sharpe & 0.53 & 0.86 \\
\hline & trades per year & 6.84 & 4.49 \\
\hline & $p$-value & 0.00 & 0.00 \\
\hline \multirow{8}{*}{$\begin{array}{l}\text { Panel B: } \\
\text { Observations excluding } \\
\text { days of U.S. } \\
\text { intervention }\end{array}$} & $\mathrm{N}$ & 5016 & 5740 \\
\hline & $100 * A R$ & 4.54 & 8.01 \\
\hline & $100 *$ std. & 0.67 & 0.61 \\
\hline & tstatistic & 1.91 & 3.98 \\
\hline & Sharpe & 0.43 & 0.83 \\
\hline & trades per year & 7.35 & 4.59 \\
\hline & $p$-value & 0.01 & 0.00 \\
\hline & Markov p-value & 0.12 & 0.17 \\
\hline \multirow{8}{*}{$\begin{array}{l}\text { Panel } \mathrm{C} \text { : } \\
\text { Observations excluding } \\
\text { days prior to U.S. } \\
\text { intervention }\end{array}$} & N & 5015 & 5739 \\
\hline & $100 * A R$ & 1.19 & 5.50 \\
\hline & $100 *$ std. & 0.64 & 0.60 \\
\hline & tstatistic & 0.52 & 2.78 \\
\hline & Sharpe & 0.12 & 0.58 \\
\hline & trades per year & 7.46 & 4.68 \\
\hline & $p$-value & 0.16 & 0.04 \\
\hline & Markov $p$-value & 0.00 & 0.00 \\
\hline
\end{tabular}

NOTES: N denotes the number of observations. The difference between the number of observations in panels $A$ and $B$ is not equal to the number of in-market interventions because some interventions occurred on days when the exchange rate was missing. $100 * A R$ is the annual return in percentage terms, and $100 *$ Std is the standard deviation of the series in percentage terms. The t statistic tests the null hypothesis that the mean excess return is zero. P-value is the fraction of randomly drawn returns that would have a mean at least as large as the mean return generated by the trading rule. Panel $B$ excludes returns from $t$ to $t+1$ when the U.S. authorities intervene on day $t$. Panel Cexcludes returns from t-1 to $t$ when the U.S. authorities intervene on day $t$. The row labeled Markov p-value is the fraction of samples with simulated intervention series whose returns were lower than those produced by removing actual intervention series on either the day of intervention or the day prior to intervention.

Panel $B$ of Table 2 shows the results of the rule with the returns from $t$ to $t+1$ removed if there is intervention on day $t$. There is some evidence that the returns are

\footnotetext{
${ }^{12}$ See Neely (1997) for more extensive discussion of risk measures, including the CAPM beta.

${ }^{13}$ LeBaron used data from DRI, collected at 9:00 a.m. Eastern time prior to October 9, 1986, and at 11:00 a.m. Eastern time to the present.
} 
Table 3

Sign Agreement

\begin{tabular}{lcccc} 
& \$/ DM & s.e. & \$/ JY & s.e. \\
\cline { 2 - 5 } Observations & 971 & - & 243 & - \\
$z(t), l(t+1)$ & 0.27 & 0.01 & 0.13 & 0.02 \\
$z(t), r(t)$ & 0.59 & 0.02 & 0.69 & 0.03 \\
$l(t+1), r(t)$ & 0.27 & 0.01 & 0.30 & 0.03
\end{tabular}

NOTES: Columns 2 and 4 indicate the fraction of the days of U.S. in-market intervention in which the signs of the intervention (on day $t+1$ ), the signs of the technical trading rule signal (on day $t$ ) and the signs of the return to holding dollars (from $t$ to $t+1$ ) were equal. Columns 3 and 5 are the standard errors of those estimates.

${ }^{14}$ The returns in Panel $\mathrm{C}$ to the \$ DM rule are reduced somewhat more when data similar to those in LeBaron (1996) are used. Results also differ from those obtained by LeBaron because of the longer sample period. lower when there is no intervention on day $t$. With these returns removed, the mean annual return for the \$/DM rule was 110 basis points lower and that of the $\$ / J Y$ rule was 40 basis points lower.

Panel $\mathrm{C}$ of Table 2 shows the analogous results on returns from $t$ to $t+1$ conditional on no intervention on day $t+1$. The timing was that used by LeBaron (1996). M ean returns are about 3 percentage points lower when there is no intervention on day $t+1$ than they would be with all observations. ${ }^{14}$ The returns to the $\$ / D M$ rule are no longer statistically significant and Sharpe ratios are much lower. Could this result be due to random removal of returns? No. LeBaron shows, and we confirm in this exercise, that randomly removing returns is very unlikely to reduce returns as much as removing observations of days before intervention. In panels $B$ and $C$ of Table 2, the last row shows the fraction of samples with randomly removed returns in which the simulated returns were as low as the returns in which the actual intervention data had been removed. The simulated return series were created by generating simulated intervention series by a calibrated M arkov process and removing returns in which the generated intervention was non-zero on day $t+1$.

Does U.S. intervention tend to occur with or against the signals generated by the technical trading rules? The first row of Table 3 shows the fraction of intervention days (day $t+1$ ) on which the U.S. authorities were buying dollars on $t+1$ while the technical rule signals (day t) also recommended buying dollars. This fraction was 27 percent for the $\$ / D M$ and 13 percent for the $\$ /$ JY. The second row of Table 3 shows the fraction of the time that the technical signal was of the same as the return to holding dollars. These figures were 59 percent for the $\$ / D M$ and 69 percent for the $\$ / J Y$. These are the fractions of the times that the technical trading rule was making money on days of intervention for each currency. The third row shows that intervention and the return to holding the foreign currency were of the same sign only 27 percent of the time for the DM and 30 percent of the time for the JY. In other words, intervention is generally against the position taken by technical traders; the technical traders are guessing the sign of the excess return correctly, and intervention tends to be in the unprofitable directionat least in the short term. Taken at face value, these correlations suggest that traders should bet against U.S. intervention.

There are several ways to interpret these results. First, the U.S. authorities may be creating predictable price patterns in otherwise efficient markets, handing money to technical traders. Second, official intervention and predictable trends in foreign exchange markets may be driven by some common factor.

The argument that the profits of technical trading rules are merely the result of transfers of money from central bankers to technical traders requires explanation. Szakmary and Mathur (1997) propose the following mechanism: Suppose that the central bank sought to smooth adjustment of exchange rates to new equilibrium levels. The central bank could lean against the wind and-if intervention proved effective- slow the adjustment of exchange rates. This tactic could enable technical traders to make money by buying from the central bank as it was selling. In contrast, in the absence of central bank intervention, the exchange rate would adjust completely before the technical traders could act.

It is important to understand that U.S. intervention may not be causing the appar- 
ently higher excess returns to trading rules but may merely be associated with them. Both may be driven by a common factor. LeBaron (1996) and Szakmary and M athur (1997) consider this idea carefully and search for a common factor driving both the intervention and the returns to the trading rules. While neither study finds evidence of such a factor, each is careful not to rule out this interpretation. Fully resolving this issue is beyond the scope of this article. The fact that both LeBaron (1996) and the results presented here find that the highest returns precede intervention argues that intervention is not causing the returns. We are content to document the fact that extrapolative trading rules tend to trade against U.S. intervention and to make excess returns during these periods.

\section{THE PROFITABILITY}

\section{OF U.S. INTERVENTION}

The goal of foreign exchange intervention is to maintain orderly market conditions or-perhaps- to assist in achieving macroeconomic goals like price stability or full employment. Therefore, it cannot be emphasized strongly enough that the profitability of foreign exchange intervention is not a necessary condition for the intervention to be justified. Nevertheless, monetary authorities have also been concerned with careful stewardship of public funds (Federal Open Market Committee, 1990). The results of the previous section, showing that technical trading rules take positions contrary to the intervention conducted by the U.S. authorities, raise questions about the profitability of that intervention. Leahy (1995), however, shows that U.S. foreign exchange intervention operations have made economically significant excess returns over the period from March 1973 through December 1992. This section reviews and extends those results.

How does one calculate the profitability of past intervention operations? We can determine the present value of a past intervention by comparing the actual current value of the assets held by U.S. monetary authorities to the value of the portfolio that would have existed in the absence of that intervention. For example, if the U.S. authorities bought $\$ 1$ million worth of U.S. dollar-denominated securities in exchange for an equal amount of DM securities on January 1,1980 , the value of that intervention on January 2,1980 , would be the overnight return to the dollar securities less the overnight return that the U.S. authorities would have obtained on the DM securities:

(6)

$$
\begin{aligned}
& \text { Profit }_{1 / 2 / 80}=\$ 1,000,000 \\
& {\left[\left(1+i_{1 / 1 / 80}^{U S}\right)-\frac{S_{1 / 2 / 80}}{S_{1 / 1 / 80}}\left(1+i_{1 / 1 / 80}^{D M}\right)\right]}
\end{aligned}
$$

where $i_{1 / 1 / 80}^{U S}$ is the U.S. dollar interest rate prevailing on January $1,1980, \mathrm{i}_{1 / 1 / 80}^{\mathrm{DM}}$ is the DM interest rate and

$$
\frac{S_{1 / 2 / 80}}{S_{1 / 1 / 80}}
$$

is the rate of appreciation of the DM against the dollar from January 1 to January 2, 1980. Of course the return to the DM asset is the opportunity cost of the intervention. The value of the intervention on January 1, 1997, would be determined by the stream of interest earned on the dollar-denominated asset minus the interest and currency appreciation-or depreciation - that would have been earned on the DM assets that were sold on January 1, 1980:

(7) $\operatorname{Profit}_{1 / 1 / 97}=\$ 1,000,000$.

$$
\begin{aligned}
& {\left[\left(1+i_{1 / 1 / 80}^{U S}\right)\left(1+i_{1 / 2 / 80}^{U S}\right) \ldots\left(1+i_{12 / 31 / 96}^{U S}\right)-\right.} \\
& \left.\frac{S_{1 / 1 / 97}}{S_{1 / 1 / 80}}\left(1+i_{1 / 1 / 80}^{D M}\right)\left(1+i_{1 / 2 / 80}^{D M}\right) \ldots\left(1+i_{12 / 31 / 96}^{D M}\right)\right] \\
& =\$ 1,000,000 \cdot\left[\prod_{t=1 / 1 / 80}^{12 / 31 / 96}\left(1+i_{t}^{U S}\right)-\right. \\
& \left.\frac{S_{1 / 1 / 97}}{S_{1 / 1 / 80}} \prod_{t=1 / 1 / 1 / 80}^{12 / 31 / 96}\left(1+i_{t}^{D M}\right)\right]
\end{aligned}
$$

Conversely, if the U.S. authorities intervene to sell dollars, they equivalently buy foreign exchange. The value of such an intervention is determined by the return to the foreign asset less the return to holding dollardenominated assets. The current value 


\section{Table 4}

Results of U.S. Of cial Foreign

Exchange Intervention

\begin{tabular}{|l|rr} 
& \$ / DM & \$ / JY \\
\cline { 2 - 3 } Cumulative net intervention & 6716 & 785 \\
Cumulative gross intervention & 81844 & 32302 \\
\hline Terminal dollar position & 36864 & -970 \\
\hline Foreign currency position 1 & -22367 & 7407 \\
\hline Foreign currency position 2 & -34416 & 857544 \\
\hline Profits & 14497 & 6437 \\
\hline Exchange rate as of 1/ 1/97 & 1.5387 & 115.77 \\
\hline Profits if \$ is 20\% higher & 18225 & 5202 \\
\hline Profits if \$ is 20\% lower & 8906 & 8289 \\
\hline \% right & 0.63 & 0.82 \\
\hline \#interventions & 1198 & 287 \\
\hline
\end{tabular}

NOTES: The first row is the cumulative net intervention

$$
\left(\sum_{t=3 / 1 / 73}^{12 / 31 / 96} I_{t}\right)
$$

while the second is gross intervention

$$
\left(\sum_{t=3 / 1 / 73}^{12 / 31 / 96}\left|I_{t}\right|\right) \text {. }
$$

${ }^{15}$ This exercise follows Leahy's assumptions that U.S. dollardenominated assets would have eamed the 3-month T-bill rate and that German assets would have eamed the German 3-month interbank rate less 25 basis points. J apanese yendenominated assets would have earned the "over-2. month-end" loan rate prior to March 2, 1979, and the 3month Gensaki rate after that date. Interest rates obtained over weekends and holidays are set equal to those obtained the prior business day.

${ }^{16}$ The author thanks Michael $P$. Leahy for assistance in verifying the intervention data used in this article.
The profits (row 6) are the sum of the terminal dollar position (row 3 ) and the terminal foreign currency position, in dollars (row 4). The terminal foreign currency position, in dollars, and in the foreign currency are in rows 4 and 5 , respectively. Row 7 shows the exchange rate as of $1 / 1 / 97$ in units of foreign currency per dollar. Rows 8 and 9 show the robustness of the profitability results to a 20 percent swing in the terminal value of the exchange rate. Row 10 shows the percentage of interventions that increased terminal profits. The final row shows the total number of days in which the sum of in-market and with-customer interventions was non-zero during the sample.

(profitability) of all past intervention operations may be calculated by summing the current value of these past interventions:

$$
\begin{aligned}
\operatorname{Profit}_{1 / 1 / 97} & =\sum_{\mathrm{t}=3 / 1 / 73}^{12 / 31 / 96} \mathrm{I}_{\mathrm{t}} \cdot\left[\prod_{\mathrm{j}=\mathrm{t}}^{12 / 31 / 96}\left(1+\mathrm{i}_{\mathrm{j}}^{\mathrm{US}}\right)\right. \\
& \left.-\frac{\mathrm{S}_{1 / 1 / 97}}{\mathrm{~S}_{\mathrm{t}}} \prod_{\mathrm{j}=\mathrm{t}}^{12 / 31 / 96}\left(1+\mathrm{i}_{\mathrm{j}}^{\mathrm{DM}}\right)\right],
\end{aligned}
$$

where the profit is in millions of U.S. dollars and $\mathrm{I}_{\mathrm{t}}$ is the amount of U.S. official foreign exchange intervention on day $t$ in millions of U.S. dollars.

The expression for the profitability of intervention operations is closely related but not identical to the expression for the returns to following the technical trading rule given in Equation 4. The expression for the technical trading-rule return is the arithmetic mean of an approximation to continuously compounded returns for traders who are switching between equally-sized long and short positions according to the signals of the trading rule. The approximate excess overnight return on each day's position is evaluated, and the mean of those returns is cal culated and reported. In contrast, the expression for the profitability of the U.S. official intervention operations is the dollar increase in the value of assets held by the U.S. authorities on January 1, 1997, caused by interventions of varying sizes.

Leahy (1995) examined the profitability of in-market and with-customer U.S. interventions in DM and JY from M arch 1, 1973, through December 31, 1992. ${ }^{15}$ W hile emphasizing that his calculations were only approximations - exact transaction prices and interest rates used in the intervention portfolio were unavailable- Leahy (1995) concluded that past DM operations would have increased the value of the portfolio held by the U.S. authorities by over $\$ 12.3$ billion as of January 1, 1993, and operations in the JY would have increased the value by over $\$ 4.2$ billion.

A subsequent revision to the intervention data and extending the intervention sample to December 31, 1996, does not change Leahy's conclusions substantially. ${ }^{16}$ Table 4 shows that intervention operations in the DM earned almost $\$ 14.5$ billion, and those in the JY made almost $\$ 6.5$ billion for the U.S. authorities. Cumulative intervention was almost $\$ 82$ billion in DM and about $\$ 32$ billion in JY. Intervention has been relatively even-handed, with theU.S. authorities buying and selling almost equal amounts of dollars. Net intervention was about $\$ 6.7$ billion in the DM and only $\$ 0.79$ billion in the JY. 
Figure 1 updates results presented in Leahy (1995) on the profitability of U.S. intervention in the \$/DM market. The top panel shows the cumulative contribution of intervention operations to the value of the U.S. authorities' portfolio on January 2 , 1997, the first business day of 1997. Intervention operations in the late 1970s, late 1985 , and the late 1980s were the most profitable. The paucity of interventions during 1981-84 and 1992-96 produces the flatness of the graph during those periods. The second panel shows cumulative interventions in the DM market; there were substantial purchases of dollars in the DM market in the late 1970s and 1990s and substantial sales in about 1980 and again in the late 1980s. Finally, the third panel shows the $D M / \$$ exchange rate over the period.

Of course, the excess return to past intervention activities as of January 1, 1997, depends on the value of the exchange rate on that date. To test the robustness of the results to swings in the value of the exchange rate, we again follow Leahy's procedure and recalculate the profits under two counterfactuals: (1) that the foreign exchange value of the dollar was 20 percent higher than it actually was; (2) that the dollar's value was 20 percent lower than it actually was. These swings still leave the minimum profits of the U.S. authorities at more than $\$ 8.9$ billion for the DM and more than $\$ 5$ billion for the JY. These results suggest that that the U.S. authorities' intervention activities have made significant economic profits over the period covering March 1973 through December 1996. ${ }^{17}$

\section{RECONCILING THE RESULTS}

The results on technical trading rules and foreign exchange intervention, described above, indicate that technical traders make a substantial portion of their profits on days of foreign exchange intervention by U.S. authorities, and the positions the technical traders hold are usually contrary to the direction of the intervention. This finding seems to suggest that U.S. foreign exchange intervention must lose money, so the smart money bets against it. On the other hand, the results outlined in the previous section show that U.S. intervention has generated excess profits for the intervention authorities over the same time period. In other words, trading in the same relative size and direction as U.S. intervention operations would have been profitable. This section explains these apparently contradictory results by referring to the varying magnitudes of interventions and returns and the differing return horizons of official intervention operations and technical trading rules.

Before discussing the reasons why the results are not contradictory, one should note that there are several procedural differences between Leahy (1995) and LeBaron (1996): They evaluated the profitability of positions in slightly different ways, and they used slightly different measures for exchange rates, interest rates, and central bank intervention. These changes in the procedures or data do not al ter the conclusions that extrapolative trading rules make positive excess returns in positions contrary to official intervention but that U.S. foreign exchange intervention is ultimately profitable.

First, it is possible for two rules with constant position sizes to trade against each other most of the time and still make money. Panel A of Table 5 shows a simple numerical example of two rules with constant-sized positions and constant-sized returns that disagree with each other most of the time, yet each trades profitably most of the time and each makes money. The table shows the return to a dollar position in column 2, while the signals from the technical trading rule and the intervention are in columns 3 and 6 , respectively. These signals determine the sign, but not the magnitude, of the respective positions (columns 4 and 7). In this example, each of the rules just breaks even when the two disagree but each makes positive returns when they agree. This simple example cannot explain the facts of intervention and technical trading-rule profits, however. While Table 4 shows that 63 percent of DM interventions and 82 percent of $\mathrm{JY}$

\footnotetext{
${ }^{17}$ Sweeney (1997) advocates adjusting central bank intervention profits for risk and discusses testing those profits for statistical significance.
} 


\section{Figure 1}

The Profitability of Of cial U.S. Intervention in the \$/DM Market and the Long-Run Equilibrium of the Exchange Rate

Cumulative Profits from Intervention

Billions of U.S. dollars

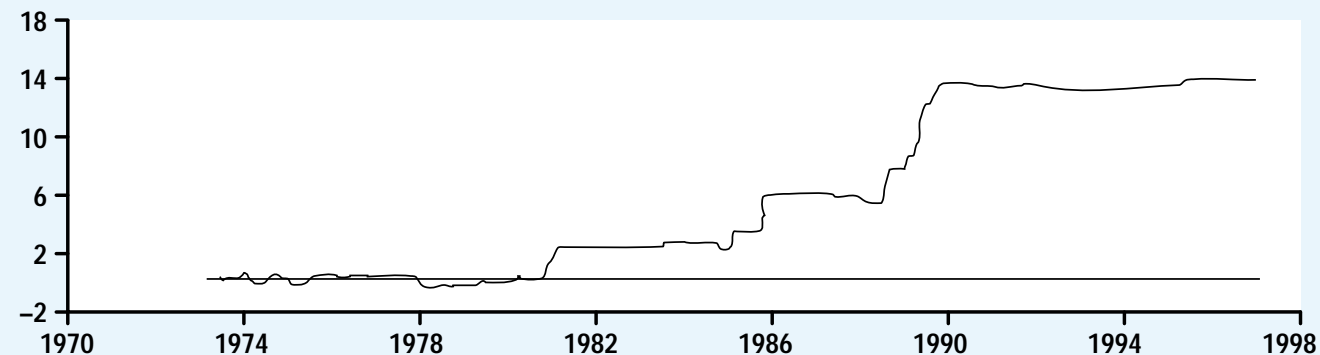

Cumulative Dollar Purchases Against DM

Billions of U.S. dollars

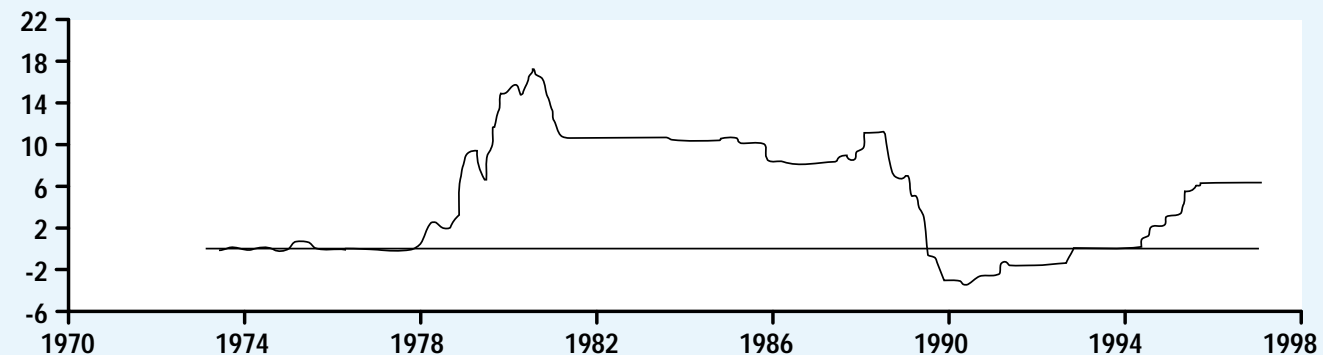

DM/\$ Exchange Rate

DM per \$

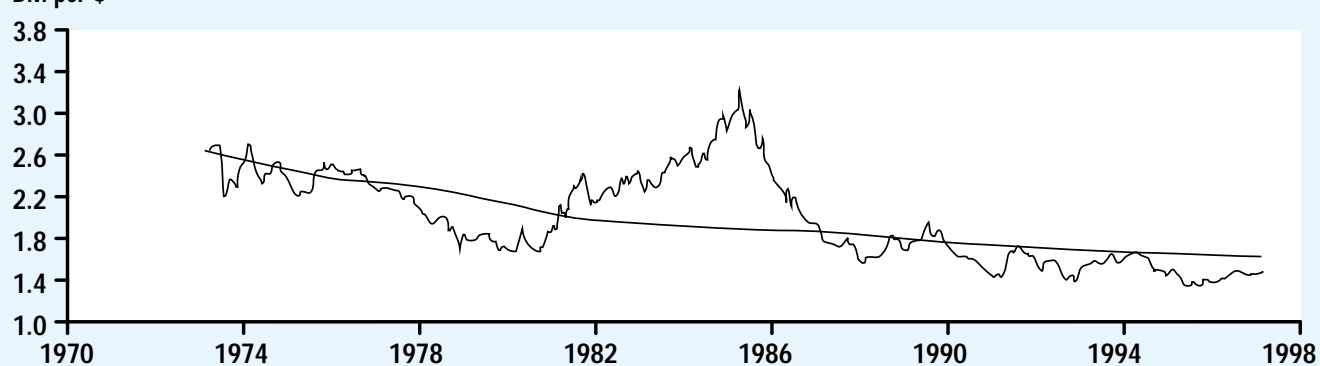

U.S. Intervention

Millions of U.S. dollars

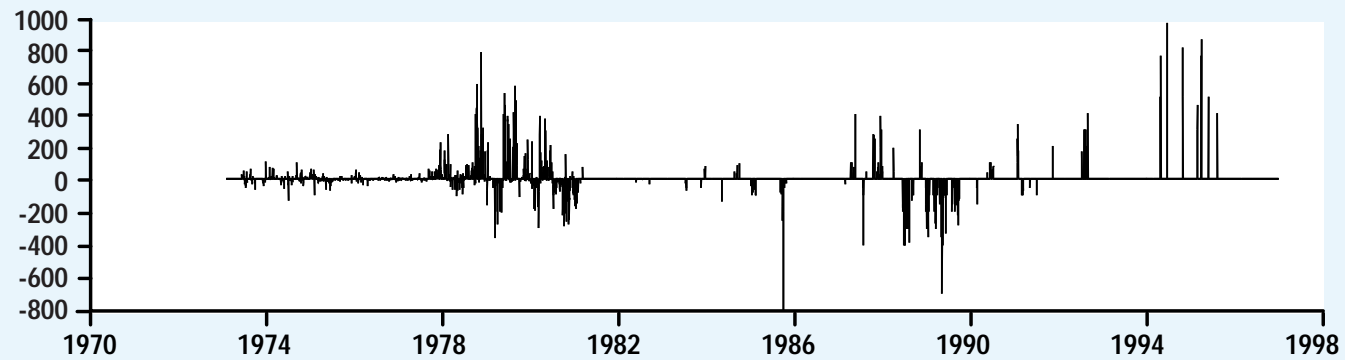


Hypothetical Numerical Examples

\begin{tabular}{|c|c|c|c|c|c|c|c|c|}
\hline & Period & \$ Return & $\begin{array}{l}\text { TTR } \\
\text { Signal }\end{array}$ & $\begin{array}{l}\text { TTR } \\
\text { Position } \\
\text { Size }\end{array}$ & $\begin{array}{l}\text { TTR } \\
\text { Return }\end{array}$ & $\begin{array}{l}\text { CBI } \\
\text { Signal }\end{array}$ & $\begin{array}{l}\text { CBI } \\
\text { Position } \\
\text { Size }\end{array}$ & $\begin{array}{l}\text { CBI } \\
\text { Return }\end{array}$ \\
\hline \multirow[t]{4}{*}{ Panel A } & 1 & -1 & Buy & +1 & -1 & Sell & -1 & +1 \\
\hline & 2 & -1 & Sell & -1 & +1 & Buy & +1 & -1 \\
\hline & 3 & +1 & Buy & +1 & +1 & Buy & +1 & +1 \\
\hline & & & \multicolumn{2}{|c|}{$67 \%$ right } & Profit=1 & $67 \%$ right & & Profit=1 \\
\hline \multirow[t]{4}{*}{ Panel B } & 1 & +1 & Buy & +1 & +1 & Sell & -0.5 & -0.5 \\
\hline & 2 & -1 & Sell & -1 & +1 & Buy & +0.5 & -0.5 \\
\hline & 3 & +1 & Sell & -1 & -1 & Buy & 2 & 2 \\
\hline & total & & \multicolumn{2}{|c|}{$67 \%$ right } & Profit=1 & $33 \%$ right & & Profit=1 \\
\hline
\end{tabular}

NOTES: Column 2 is the return to a dollar position, while columns 3 and 6 are the signals from the TRR and the intervention, respectively. These signals determine the sign, but not the magnitude, of the respective positions (columns 4 and 7 ). The returns to the rules shown in columns 5 and 8 are the products of the returns to the dollar positions (column 2 ) and the signed positions ( 4 and 7 ).

interventions eventually made positive profits, only 45 percent of DM interventions and 50 percent of $\mathrm{JY}$ interventions made positive profits on the first day after intervention.

A second possibility is that varying position sizes and/or varying return sizes can permit a trading strategy (intervention) to be profitable while being on the unprofitable side of the market most of the time and usually at odds with another profitable strategy (technical trading). Panel B of Table 5 provides a simple numerical example in which the technical trading rule is right 67 percent of the time. The intervention rule is right 33 percent of the time. Both make positive excess returns, but the two never agree with each other's signals. The intervention rule makes positive excess returns because the magnitude of the intervention is unusually large for the period in which the sign of the intervention is in the profitable direction. A similar example could be constructed in which the intervention position size is constant, but the intervention rule could make positive excess returns while being unprofitable most of the time, if it is profitable during the periods with large returns. This example, by itself, does not explain the profitability of intervention, however. On average, profits are negative on the day after DM intervention and only very slightly positive on the day after $J Y$ intervention.

A third reason why the results may not be in contradiction is that the investment horizons for the technical traders and the U.S. authorities may differ. That is, the technical traders could be making excess returns trading contrary to U.S. intervention over a relatively short horizon after the intervention occurs-closing out their position before positive returns have accrued to the intervention position. That is, the U.S. authorities might be taking a long view, perhaps losing money for short periods after the intervention but benefiting from a long-run tendency for cumulative returns to the intervention position to be positive. When we compare the average length of a position in a currency for technical rules and official interventions, we conclude that this may be the case. Table 2 shows that the technical rules trade about four to seven times per year or, equivalently, that the average position is held for only two to three months before it is reversed. In contrast, the second panel of Figure 1 


\section{Figure 2}

Profits to U.S. Foreign Exchange Intervention Activities by Investment Horizon
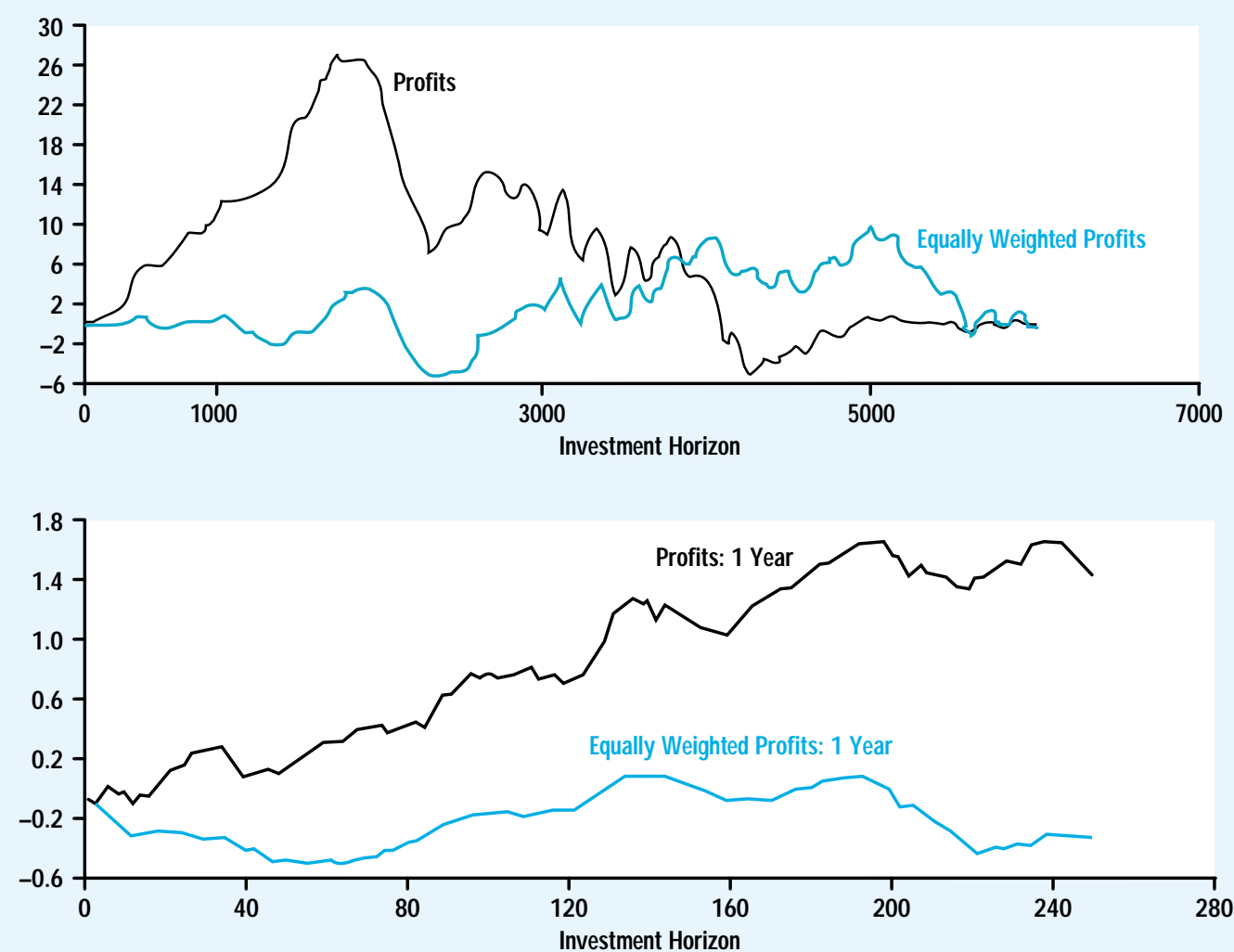

NOTES: The function in the left panel is the mean profit after $n$ days over all interventions that occurred $n$ or more days before the end of the sample. Indexing such interventions by $k$ and denoting the date of the $k$ th intervention by $k_{t}$, the $n$th observation is:

$$
\text { MeanProfit }_{n}=\frac{1}{K} \sum_{k=1}^{K} I_{k} \cdot\left[\prod_{j=k}^{k_{t}+n-1}\left(1+i_{j}^{U S}\right)-\frac{S_{k_{t}+n}}{S_{k_{t}}} \prod_{j=k_{t}}^{k_{t}+n-1}\left(1+i_{j}^{D M}\right)\right] \text {. }
$$

The equally weighted function in the right panel of Figure 2 , would replace $I_{k}$ with sign $\left(I_{k}\right) \mid \|$, where $\mid \|$ denotes the mean magnitude of non-zero interventions.

shows that cumulative intervention in the DM was positive between 1978 and 1989 and negative between 1989 and the end of 1994. That is, (cumulative) intervention positions tend to be maintained for years before they are effectively netted out by intervention in the opposite direction.

To further examine the conjecture that U.S. authorities make excess profits by trading with long-run trends in exchange rates, we require some measure of the long-run tendency of exchange rate returns. We can cal culate such a longrun tendency in a crude way with reference to purchasing power parity (PPP), which holds that changes in the exchange rate may be explained by differences in countries' inflation rates. ${ }^{18}$ That is, the dollar will tend to depreciate against the DM to the extent that U.S. inflation exceeds German inflation. Of course, this method ignores the contribution of interest rate differentials on exchange rate returns. 


\section{Figure 3}

Mean Cumulative Returns to the MA $(1,150)$ Rule on \$/DM

Data by Investment Horizon
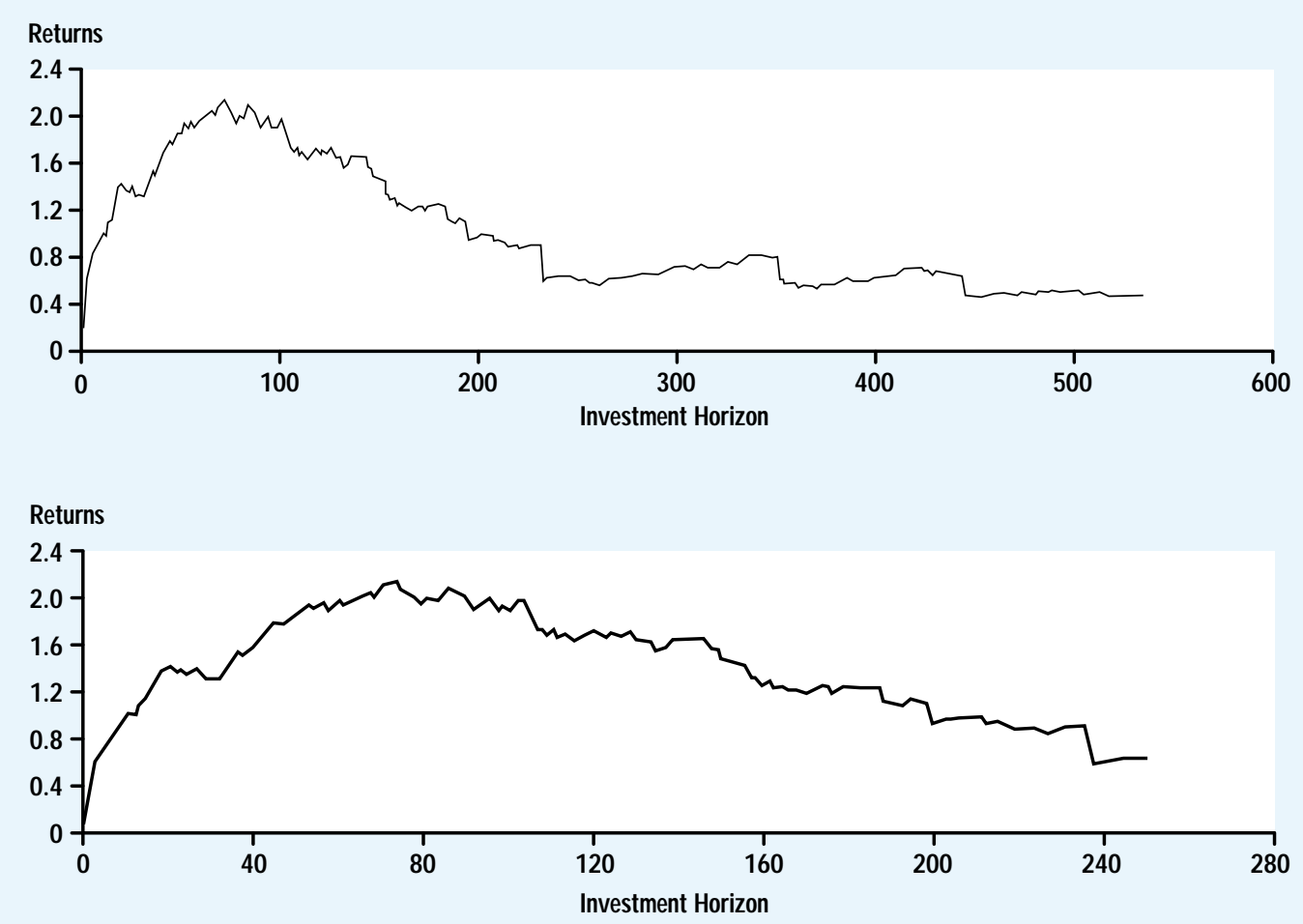

To construct the simple PPP-based measure of the long-run tendency of the exchange rate, we first regress monthly domestic and foreign price series on a constant, on a time trend, and on lagged prices to obtain predicted values for each price series. We then create daily foreign and domestic price series by linear interpolating daily predicted values from the monthly predicted values. We predict daily values for the long-run tendency of the exchange rate with a regression of actual daily exchange rates on the interpolated foreign and domestic daily price series. The third panel of Figure 1 shows that this crude measure of long-run tendencies seems to fit the \$/DM exchange rate data well.

The third and fourth panels of Figure 1 also seem to show that the U.S. authorities tend to buy dollars when the price of dollars in terms of DM is bel ow its long-run tendency and sell dollars when the DM price of dollars is above its long-run tendency. Indeed, the heaviest interventions- 1978-79, 1985, and 1994-95look to be associated with some of the largest deviations from the PPP-implied value of the exchange rate. This result suggests that one rationale for official U.S. foreign exchange intervention may be to correct perceived misalignment (large undervaluations or overvaluations) of the dollar, and that the intervention may be profitable over the long horizon because it tends to buy low and sell high. Contingency analysis of intervention and the sign of deviation from long-run equilibrium corroborates that most official intervention in both the DM and JY markets is stabilizing in the sense of being in the direction of long-run equilibrium. ${ }^{19}$ For example, intervention is in the "stabilizing" direction 52 percent of the time for the DM and 63
${ }^{19}$ The word "stabilizing" is used for brevity in this paragraph to describe any intervention that buys below long-run equilibrium or sells above long-run equilibrium. Use of this word does not imply that the intervention influences the exchange rate in any way. 
percent of the time for the JY. Considering only interventions larger in absolute value than the mean absolute non-zero intervention strengthens this conclusion: 72 percent and 77 percent of "large" DM and JY interventions, respectively, are in the stabilizing direction. Refining the criteria further - to also include only interventions in which the dollar was more than 2 percent away from its equilibrium value- pushes the proportion of DM interventions in the stabilizing direction to 74 percent and the corresponding proportion of JY interventions to 90 percent.

How profitable is U.S. intervention as a function of the time since the intervention? The top panel of Figure 2 shows the mean cumulative profits to U.S. interventions in DM as a function of the investment horizon using weighted profits. Larger interventions receive proportionately more weight- and equally weighted profits-profits to all interventions receive the mean absolute intervention weight. The bottom panel of Figure 2 displays the information in the top panel over the first 250 days. ${ }^{20}$ The weighted profits are not significantly negative at investment horizons of less than 18 years ( 4,500 days / 250 business days in a year), and they turn significantly positive after four weeks ( 20 days). In contrast, the equally weighted profits are often negative at all horizons and are always negative at horizons of less than 30 weeks ( 150 days). In other words, the U.S. authorities often intervene in an unprofitable directionover a horizon of months-but when the product of the intervention position and the cumulative return is large, the position is much more likely to produce positive excess profits, even over a horizon of a few months. The results for the JY interventions show no tendency for larger interventions to be more profitable at short horizons, but such interventions do tend to be more profitable over the length of the sample.

Figure 2 can be misleading, however. One might think that because larger interventions- positive or negative- are slightly more likely to be profitable, and larger returns are also positively associated with profitable interventions, then total profits from intervention would have been lower if all the interventions had been of average size. This would be incorrect. There is a negative association between the size of intervention and the magnitude of returns that offsets the positive association between the size of interventions and the likelihood of the interventions being profitable.

In contrast to the results for intervention, Figure 3 shows that the mean cumulative returns to the MA $(1,150)$ rule on \$/DM data are positive at all investment horizons. Again, the top panel shows all investment horizons (no position is held over 550 days and few are held longer than 150 days), while the bottom panel shows the performance over the first 250 days.

\section{CONCLUSION}

Recent research in international finance has turned up a correlation between returns to technical trading rules and periods of central bank intervention. Specifically, technical trading rules tend to trade contrary to the direction of U.S. intervention, and returns to the technical rules are unusually high during, and prior to, periods of central bank intervention. This phenomenon might suggest that U.S. interventions in the foreign exchange market lose money. The best evidence, however, is that U.S. foreign exchange intervention has been profitable over the same sample period. Does a smart trader bet with U.S. intervention or against it? This article resolves the apparent contradiction between these facts by showing that the profits on official U.S. intervention come both because of a much longer investment horizon than the technical rules and because profitable interventions are more likely than unprofitable interventions to involve both large interventions and large cumulative returns.

Future research on this topic will examine the source of the link between trading-rule profits and central bank intervention. In particular, does intervention create tradingrule profits or are both driven by some common process? 


\section{REFERENCES}

Adams, Donald B., and Dale W. Henderson. "Definition and Measurement of Exchange Market Intervention," Staff Studies No. 126, Board of Governors of the Federal Reserve System, September 1983.

Bank for International Settlements. Central Bank Survey of Foreign Exchange and Derivatives Market Activity, May 1996.

Corrado, Charles I., and Dean Taylor. "The Cost of a Central Bank Leaning against a Random Walk," Journal of Intemational Money and Finance (September 1986), pp. 303-14.

DeLong, J. Bradford, Andrei Shleifer, Lawrence H. Summers, and Robert J. Waldmann. "Noise Trader Risk in Financial Markets," Journal of Political Economy (August 1990), pp. 703-38.

Dooley, Michael P., and J effrey R. Shafer. "Analysis of Short-Run Exchange Rate Behavior: March 1973 to November 1981," Floating Exchange Rates and the State of World Trade Payments, David Bigman and Teizo Taya, eds., Ballinger, 1983.

Edison, Hali J. "The Effectiveness of Central-Bank Intervention: A Survey of the Literature After 1982," Special Papers in Intermational Economics No. 18, Department of Economics, Princeton University, 1993.

Federal Open Market Committee. "Minutes of the Federal Open Market Committee Meeting, July 27, 1990."

Friedman, Milton. "Why the Twin Deficits Are a Blessing," Wall Street Journal (December 14, 1988).

. . . . "The Case for Flexible Exchange Rates," Essays in Positive Economics, University of Chicago Press, 1953, pp. 157-203.

Goodhart, Charles A.E., and Thomas Hesse. "Central Bank Intervention Assessed in Continuous Time," Joumal of International Money and Finance (August 1993), pp. 368-89.

Humpage, Owen. "U.S. Intervention: Assessing the Probability of Success," Federal Reserve Bank of Cleveland Working Paper 9608, January 1998.

. "Institutional Aspects of U.S. Intervention," Economic Review, Federal Reserve Bank of Cleveland (1994:1), pp. 2-19.

Kritzman, Mark. "Serial Dependence in Currency Returns: Investment Implications," Journal of Portfolio Management (Fall 1989), pp. 96-102.

Leahy, Michael P. "The Profitability of U.S. Intervention in the Foreign Exchange Markets," Journal of International Money and Finance (December 1995), pp. 823-44.

LeBaron, Blake. "Technical Trading Rule Profitability and Foreign Exchange Intervention," NBER Working Paper 5505, March 1996.

Mayer, Helmut, and Hiroo Taguchi. "Official Intervention in the Exchange Markets: Stabilising or Destabilising?" Bank for International Settlements Economic Paper 6, March 1983.

Neely, Christopher ). "Technical Analysis in the Foreign Exchange Market: A Layman's Guide," this Review (September/ October 1997), pp. 23-38 and Paul Weller. "Technical Analysis and Central Bank Intervention," Federal Reserve Bank of St. Louis Working Paper 97 002A, January 1997.

Salant, Stephen W. "Profitable Speculation, Price Stability, and Welfare," Intemational Finance Discussion Paper 54, Board of Govemors of the Federal Reserve System, November 1974.

Sweeney, Richard ]. "Beating the Foreign Exchange Market," Journal of Finance (March 1986), pp. 163-82.

. "Do Central Banks Lose on Foreign-Exchange Intervention? A Review Article," Journal of Banking and Finance (December 1997), pp. 1667-84.

Szakmary, Andrew C., and Ike Mathur. "Central Bank Intervention and Trading Rule Profits in Foreign Exchange Markets," Journal of International Money and Finance (August 1997), pp. 513-36. 